\title{
Platelet glycoprotein IIb/IIla inhibitors in acute ischemic stroke
}

\author{
Sudhir Kumar, G. Rajshekher, Subhashini Prabhakar \\ Stroke Unit, Department of Neurological Sciences, Apollo Hospitals, Jubilee Hills, Hyderabad, India
}

\begin{abstract}
Acute ischemic stroke (AIS) is a common cause of morbidity and mortality worldwide. Thrombolytic therapy with tissue plasminogen activator, the only approved treatment for AIS, is received by less than $2 \%$ of patients. Moreover, there is a slight increase in hemorrhagic complications with thrombolysis. Therefore, there is a need for newer therapeutic modalities in AIS, which could be used in window periods beyond 3-6 h after stroke onset with fewer hemorrhagic complications. Glycoprotein Ilb/Illa inhibitors (GPI), after their initial success in patients with acute coronary syndromes, promised much in patients with AIS over the past decade or so. However, their exact role in patients with AIS, including the window periods and type of strokes, and the risk of symptomatic or asymptomatic hemorrhage are unclear at the moment. The current review focuses on the literature concerning the use of GPI in AIS and looks at the available evidence regarding their use. Abciximab thought to be safe and effective in initial case series and early trials, has not been shown to improve outcomes in AIS, and is associated with higher rates of hemorrhage. Tirofiban appears to be safe and effective in initial trials and there is a need to conduct further trials to establish its role in AIS.
\end{abstract}

Key words: Abciximab, acute ischemic stroke, cerebrovascular disease, platelet glycoprotein Ilb/IIla inhibitors, tirofiban

\section{Introduction}

Acute stroke is among the leading causes of death and disability worldwide. Data regarding stroke in India is limited, however, the estimated prevalence is 2 per 1000 population. ${ }^{[1]}$ In a recently published review, the crude prevalence rate of stroke was estimated to be 40 to 270 per 100,000 population, based on several community-based studies. ${ }^{[2]}$ Majority of the strokes are ischemic in nature, accounting for about $75 \%$ of all strokes. This proportion of ischemic strokes is relatively higher in the Asian as compared to Western population. ${ }^{[3]}$ Thrombolysis with recombinant tissue plasminogen activator (rt-PA) is the only proven beneficial therapy in acute ischemic stroke (AIS). Thrombolysis within 3-6 h of symptom-onset improves clinical outcomes and reduces disability in stroke patients. This benefit is at the cost of an increased rate of symptomatic intracranial hemorrhage (ICH) without a significant effect on overall mortality. In general, the benefit of thrombolysis decreases and the risks increase with progressing time after symptom onset. ${ }^{[4]}$ Despite the benefits of thrombolysis, less than $2 \%$ of eligible patients receive it, even at the best of stroke centers. ${ }^{[5]}$ The reasons include lack of adequate transport facilities, high cost of tissue plasminogen activator, lack of proper infrastructure including facilities for thrombolysis in most centers, and lack of awareness among public and doctors. ${ }^{[2,6]}$ Inability to reach hospital within a window period of $6 \mathrm{~h}$ is the most important limiting factor for the use of thrombolytic therapy ${ }^{[6]}$ Therefore, there is an urgent need for effective therapies in AIS beyond the 6-h window period, which are relatively safer (lesser risk of ICH) and more economical. Drugs that belong to the glycoprotein IIb/IIIa inhibitors (GPI) could be useful in such a scenario. The purpose of this article is to review the available evidence regarding their use in AIS.

\section{Glycoprotein IIb/IIla receptors}

GP IIb/IIIa receptors are found on the platelet surface numbering 50-60,000 per platelet. These are responsible for the final step of platelet aggregation leading to thrombus formation. In addition to thrombosis, these receptors are also involved in inflammation and atherogenesis. GP IIb/IIIa receptors belong to a class of integrins with a specificity of binding to fibrinogen.

\section{Glycoprotein Ilb/llla inhibitors}

Blockage of GP IIb/IIIa receptors interferes with the final step of platelet aggregation, which could result in better outcomes in acute coronary syndromes (ACS) and 
AIS. GPI can be classified into two groups: ${ }^{[7]}$

1. Naturally occurring peptide inhibitors- These are isolated from Viper venoms and Puff adder and are not clinically used. Examples include Trigramin, Barbourin and Kistrin.

2. Synthetic inhibitors- These are of three types:

a) Monoclonal antibodies- Abciximab, used parenterally.

b) Peptide- Eptifibatide, used parenterally.

c) Non-peptide-

i. Parenteral use, e.g. tirofiban, lamifiban;

ii. Oral use, e.g. xemlofiban, orofiban, roxifiban, lotrafiban.

GPIs in clinical use include Abciximab (ReoPro), Tirofiban (Aggrastat) and Eptifibatide (Integrillin).

\section{Clinical use of glycoprotein Ilb/Illa inhibitors}

\section{Acute coronary syndromes}

GPIs were initially used in patients with acute coronary syndromes (ACS). It was found that aggressive platelet inhibition with abciximab during primary percutaneous transluminal coronary angioplasty (PTCA) for acute myocardial infarction (MI) yielded a substantial reduction in the acute (30-day) phase for death, reinfarction, and urgent target vessel revascularization. ${ }^{[8]}$

Subsequently, other GP IIb/IIIa inhibitors were also tested in patients with ACS. Additional eptifibatide therapy resulted in reduced incidence of death and nonfatal MI at 30 days in patients with acute MI or unstable angina, as compared to the routine management with aspirin and heparin. ${ }^{[9]}$ The success seen with the usage of GPIs in ACS gave the hope that they could be useful in patients with AIS too; as both the conditions share common pathophysiologic mechanisms.

\section{Acute ischemic strokes Abciximab (ReoPro)}

Initial (Phase 1) safety study of Abciximab in AIS: In a randomized, double-blind, placebo-controlled trial designed to evaluate the safety of abciximab in AIS and to obtain pilot efficacy data, no cases of major ICH occurred among 54 patients that received the drug. ${ }^{[10]}$ Seven per cent of patients had asymptomatic ICH. At three months, there was a trend toward a higher rate of minimal residual disability (Barthel Index $>$ or $=95$ or modified Rankin scale $<$ or $=1$ ) among abciximab patients as compared with those who received placebo. It was concluded that abciximab was safe when administered up to $24 \mathrm{~h}$ after stroke onset, and it might improve functional outcome.

\section{Case series evaluating abciximab in acute ischemic}

\section{strokes}

MRI-guided trial of abciximab in AIS:

Twenty-nine patients with AIS presenting within the 3-24-h window period were treated with abciximab or placebo ${ }^{[11]}$ Treated patients showed early neurological improvement (NIH stroke scale score improvement of $4.4 \pm 3.2$ ); $45 \%$ of patients had $\geq 5$ point $\mathrm{NIH}$ stroke scale score decrease or deficit resolution. Twentyseven per cent of treated patients had a reduction of lesion size as seen on diffusion-weighted MRI, a finding uncommonly seen in untreated patients. No treatment-related symptomatic ICH or death occurred in this study.

Abciximab-heparin combination therapy in AIS:

In an open label study, 22 patients were treated with abciximab at a dose of $0.2 \mathrm{mg} / \mathrm{kg}$ bolus, followed by a 12-h infusion of $0.05 \mu \mathrm{g} / \mathrm{kg} / \mathrm{h}$, in conjunction with short course intravenous heparin, within a window of $6 \mathrm{~h}$ for anterior and $24 \mathrm{~h}$ for posterior circulation strokes. ${ }^{[12]}$ No cases of symptomatic ICH occurred and the rate of asymptomatic ICH was $12.5 \%$. Ninety-day functional outcome too appeared promising.

Abciximab-rt-PA combination therapy in AIS:

In a Phase I safety trial, five patients were treated with the combination of half-dose rt-PA $(0.45 \mathrm{mg} / \mathrm{kg})$ and abciximab $(0.25 \mathrm{mg} / \mathrm{kg}$ bolus followed by a $0.125 \mu \mathrm{g} /$ $\mathrm{kg} / \mathrm{min}$ infusion over $12 \mathrm{~h}$ ). ${ }^{[13]}$ No cases of symptomatic ICH occurred, however, one out of five experienced asymptomatic ICH. A trend of treatment efficacy was also seen.

In another study, 47 patients with acute vertebrobasilar stroke were treated with abciximab and low-dose rt-PA (FAST). ${ }^{[14]}$ The results were compared with a retrospective cohort of 41 patients, treated by intraarterial rt-PA monotherapy (median dosage: $40 \mathrm{mg}$ ). Additional PTA/stenting was performed in case of severe residual stenosis. Overall bleeding rate was higher under the combined therapy, but the symptomatic ICH rate did not differ. Thrombolysis in MI (TIMI)2/3 recanalization rate was similar (FAST, 72\%; rtPA, 68\%), but TIMI3 rate was remarkably higher under combined therapy (FAST, 45\%; rtPA, N=22\%). Neurological outcome appeared better under combined therapy (FAST versus rtPA: favorable outcome rate: $34 \%$ versus $17 \%$ ) with a significantly lower mortality rate (FAST versus rtPA: $38 \%$ versus $68 \% ; P=0.006$ ). Overall, the combination therapy of abciximab and rt-PA was better than rt-PA alone in this trial.

Reperfusion of the reoccluded artery after successful thrombolysis:

Thrombolytic therapy fails in many patients with acute ischemic stroke. The reocclusion that occurs during or immediately after successful thrombolysis may be an important treatment target because 1) this type of reocclusion involves platelet-mediated thrombotic 
mechanisms; 2) the highly potent and selective inhibition of platelet aggregation can be achieved by GP IIb/IIIa receptor inhibitors; and 3) early reperfusion is crucial for the prognosis of stroke patients. ${ }^{[15]}$

In a recent study, reocclusion occurred in four of 18 patients $(22 \%)$ with initial recanalization. ${ }^{[15]}$ Three reocclusion patients had suboptimal (TIMI 2) flow. The reoccluded arteries included the MCA in three patients and the VBA in one patient. Systemically administrated abciximab was associated with dissolution of the thrombus in all reocclusion patients within 30 to 40 min after the bolus.

Abciximab in the treatment of acute cerebral thromboembolic events during neuroendovascular procedures:

In a large series of 1373 consecutive patients who underwent neuroendovascular procedures, 29 were complicated by acute cerebral thromboembolic events that were treated with abciximab. ${ }^{[16]}$ Abciximab was administered in less than $1 \mathrm{~h}$ after the onset of the occlusion in every patient. Angiographic improvement in the TIMI grade was achieved in 29 (81\%) of 36 arteries. Three cases of ICH occurred with abciximab when administered with concurrent mechanical clot disruption; in two of these hemorrhages, rt-PA was also administered. The mean follow-up time for the living cohort was 7.54 months. Twenty-four (83\%) patients were independent at follow-up, three (10\%) were dependent at follow-up, and two (7\%) died. This study found abciximab to be safe and effective in the treatment of acute cerebral thromboembolic complications during neuroendovascular procedures.

However, the results were not so encouraging in another trial. The all stroke/neurological death rate in patients treated with heparin and GP IIb/IIIa inhibitors was $6.0 \%$ (13 events) as compared $2.4 \%$ (eight events) in the heparin-only group $(P=0.0430) .{ }^{[17]}$ Two of the four neurologically-related deaths in the GP IIb/IIIa inhibitor group resulted from ICH; there was no ICH in the heparin-only group. Based on the findings, the authors discouraged the use of abciximab in patients undergoing carotid stenting.

Therefore, one could use abciximab with caution in thromboembolic events related to endovascular procedures, and watch for any symptomatic ICH.

Phase 2 study evaluating Abciximab in AIS

\section{(AbESTT I):}

An international randomized, double-blind, placebocontrolled Phase 2 trial enrolled 400 patients within 6 $\mathrm{h}$ of onset of ischemic stroke to study the safety and efficacy of abciximab. ${ }^{[18]}$ Two hundred patients received abciximab at a bolus dose of $0.25 \mathrm{mg} / \mathrm{kg}$, followed by a 12-h infusion at a rate of $0.125 \mu \mathrm{g} / \mathrm{kg}$ per min (maximum infusion was $10 \mu \mathrm{g} / \mathrm{min}$ ). There was a slightly higher incidence of ICH in abciximab-treated patients as compared to the placebo ( $3.6 \%$ versus $1 \%$ ), however, the mortality did not increase because of this. The ICH tended to occur in patients with larger strokes and those who received other antithrombotic medications prior to inclusion in this study. A trend towards potential efficacy at three months was seen with abciximab as compared with placebo, though this difference was statistically insignificant.

Phase 3 study evaluating abciximab in AIS

\section{(AbESTT II):}

In a multicentric (112 centers), randomized, doubleblind, placebo-controlled trial, patients were randomized to receive abciximab or placebo, within 5 or $6 \mathrm{~h}$ of stroke onset (Groups 1 and 2 respectively) or $3 \mathrm{~h}$ of waking up from stroke (Group 3). ${ }^{[19]}$ After screening 8,207 patients, 221 patients were randomized to abciximab and 218 to placebo. No significant difference was seen in terms of efficacy and mRS at 90 days between the drug and placebo groups. Similarly, there was no difference at 90 days with respect to neuro-recovery, mRS 0-1, stroke recurrence and Barthel index between the two groups. However, the incidence of fatal or symptomatic ICH was significantly higher in the abciximab-treated group at both discharge/Day 5 and 90 days. Therefore, this trial demonstrated a lack of efficacy of abciximab in the treatment of patients with AIS, and no single population or subgroup seemed to benefit from this treatment.

\section{Summary of efficacy and safety studies of abciximab} on AIS

A summary of all studies using abciximab in AIS is presented in Table 1. Abciximab has been evaluated in patients with AIS in small case series and large trials. Uniformly, it has been found to be safe, except for a nonsignificant increase in the risk of bleeding complications. However, it has not resulted in any significant improvement in the functional outcome.

\begin{tabular}{|c|c|c|c|c|}
\hline Authors, Year & Agent(s) used & $\begin{array}{c}\text { Number of } \\
\text { patients }\end{array}$ & Hemorrhagic complications & Functional outcome \\
\hline AbESTT, ${ }^{[18,19]}$ & Abciximab & 54 & Major ICH- Nil, Asymp. ICH-7\% & Positive trend \\
\hline Mitsias et al., ${ }^{[11]}$ & Abciximab & 29 & Nil & Better \\
\hline Mandava et al., ${ }^{[12]}$ & Abciximab + Heparin & 22 & $\mathrm{Nil}$ & Positive trend \\
\hline Eckert et al., ${ }^{[14]}$ & Abciximab + rt-PA & 47 & Overall bleeding $\uparrow$ Symp. ICH- same & Better \\
\hline AbESTT 1, (Phase II) ${ }^{[18]}$ & Abciximab & 200 & $\mathrm{ICH} \uparrow$ Mortality- same & Positive trend \\
\hline AbESTT- II, (Phase III) ${ }^{[19]}$ & Abciximab & 221 & Mortality and $\mathrm{ICH} \uparrow$ & No change \\
\hline
\end{tabular}


The only group where it may be potentially effective is, during neuroendovascular procedures, when the incidence of thromboembolic complications reduces after using abciximab.

\section{TIROFIBAN (Aggrastat)}

Bleeding risk of tirofiban in patients with AIS

In an initial safety study, 18 patients with progressively deteriorating AIS were treated with body-weight adjusted intravenous tirofiban for a mean period of 46 $\mathrm{h}$ and compared with a matched group of 17 clinically stable AIS patients. ${ }^{[20]}$ Cerebral hemorrhage was assessed by CT scan six to ten days after symptom onset. No major ICH was observed in either group.

\section{Tirofiban-rt-PA combination therapy in AIS}

In a small, nonrandomized, open-label trial, 19 patients suffering from acute middle cerebral artery occlusion (TIMI flow Grade 0 to 1) underwent combined intravenous thrombolytic treatment using rt-PA at reduced dosages and tirofiban. ${ }^{[21]}$ All patients received a combined thrombolytic treatment with rt-PA at reduced dosages (i.e., a single 20-mg bolus in 15 cases and a 10mg bolus followed by a 40-mg infusion over $1 \mathrm{~h}$ in four cases) and body weight-adjusted tirofiban. Tirofiban was started with an infusion rate of $0.4 \mu \mathrm{g} / \mathrm{kg} / \mathrm{min}$ over half an hour followed by $0.1 \mu \mathrm{g} / \mathrm{kg} / \mathrm{min}$ for at least $48 \mathrm{~h}$. In this study, middle cerebral artery recanalization (TIMI flow Grade 2 and 3) occurred in 13 of 19 patients (68\%). The ischemic lesion on follow-up MRI was significantly smaller in patients with recanalization compared with those without recanalization $(P=0.001)$. Only patients with recanalization improved neurologically $(P<0.001)$. No cases of symptomatic ICH occurred.

In another study, 37 consecutive patients were treated with a combination of rt-PA and tirofiban (rt-PA+T). ${ }^{[22]}$ The outcome was compared to groups that received rt-PA alone or did not receive either of these drugs (controls). Clinical improvement was similar in rt-PA $+\mathrm{T}$ and rt-PA groups, as seen on mRS scores. Mortality and fatal/symptomatic ICH rates were not higher in the tirofiban-treated group.

\section{Intravenous tirofiban followed by intra-arterial} urokinase and mechanical thrombolysis in stroke

In a recent study, 21 consecutive patients with an AIS due to major cerebral arteries occlusion and a NIHSS score $>$ or $=18$ were treated with an intravenous bolus of tirofiban and heparin followed by intra-arterial administration of urokinase coupled with mechanical thrombolysis. ${ }^{[23]}$ Immediate recanalization was successful (TIMI 2-3) in 17 of 21 patients. The following day, 14 of 19 patients improved substantially and complete vessel patency (TIMI 3-4) was confirmed by digital subtraction angiography. Intracranial bleeding occurred in five of 21 patients (three symptomatic cerebral hemorrhages and two subarachnoid hemorrhages) and was fatal in three patients. Overall, at three-month follow-up the functional outcome was favorable (modified Rankin Scale score $=0-2)$ in 13 of $21(62 \%)$ patients. Death (including all causes) at 90 days occurred in six of 21 (28\%) cases.

\section{Thrombolysis with intravenous tirofiban alone}

Vertebrobasilar artery thrombolysis has been achieved with intravenous tirofiban alone with good outcomes and without symptomatic ICH. ${ }^{[24]}$

\section{Thrombolysis with intravenous tirofiban with alteplase}

In a case series, four patients with acute basilar artery thrombosis, complete arterial recanalization and good neurological outcome were achieved with a treatment combining alteplase with tirofiban. ${ }^{[25]}$ In no cases were cerebral or extracerebral hemorrhagic complications observed.

\section{Ischemic brain tissue salvaged from infarction by} tirofiban

In an open pilot study, the infarct volume (T2 lesion on MRI after one week) was smaller in tirofibantreated patients $(\mathrm{n}=10)$ compared with matched control subjects $(\mathrm{n}=10 ; P=0.029)$ with similar initial perfusion deficit. ${ }^{[26]}$

In another study, to determine the effect of systemic thrombolysis with low-dose rt-PA and the bodyweight adjusted tirofiban, lesion volumetry on magnetic resonance perfusion and diffusion images was performed, recorded before thrombolysis and on T2-weighted magnetic resonance images on Day $8 .^{[27]}$ Treatment with rt-PA and tirofiban $(\mathrm{n}=13)$ resulted in a 50\% lesion reduction $(P<0.03)$, while lesion reduction was less in rt-PA treatment $(\mathrm{n}=16)$ and absent in nontreated patients $(\mathrm{n}=18)$.

\section{Cerebral microembolism is blocked by tirofiban}

Microembolic signals (MES) as detected by transcranial Doppler ultrasound define an individual stroke risk in patients with carotid artery disease. In a recent study, 24 patients with recent cerebral or retinal embolism of arterial origin and a MES rate $>6$ per $\mathrm{h}$ on initial transcranial Doppler ultrasonography recording received tirofiban. ${ }^{[28]}$ With tirofiban, the MES rate dropped from a median (range) of 38 (9 to 324) to zero in all patients. After cessation of infusion, the inhibitory effect of tirofiban was reversible, with a significant increase of MES (median 13.5; range, 0 to 35 ; $n=16$; $P=0.001)$.

Phase 2 trial of tirofiban in acute ischemic stroke (SaTIS study)

The Safety of Tirofiban in Acute Ischemic Stroke 


\begin{tabular}{|c|c|c|c|c|}
\hline Authors, Year & Agent(s) used & $\begin{array}{l}\text { Number of } \\
\text { patients }\end{array}$ & Hemorrhagic complications & Functional outcome \\
\hline Junghans et al., ${ }^{[20]}$ & Tirofiban & 18 & $\mathrm{Nil}$ & Not studied \\
\hline Straub et al., ${ }^{[21]}$ & Tirofiban + rtPA & 19 & Nil & Better \\
\hline Seitz et al., ${ }^{[22]}$ & Tirofiban + rtPA & 37 & No increase in $\mathrm{ICH}$ & Better \\
\hline SaTIS study, 2006 & Tirofiban & 127 & $\begin{array}{l}\text { Nonsignificant increase in bleeding; } \\
\text { lower mortality }\end{array}$ & Better \\
\hline
\end{tabular}

(SaTIS) study's primary endpoint was treatment safety in patients with AIS and the secondary endpoint was clinical efficacy. ${ }^{[29]}$ Study subjects were 18 to 80 years of age, had ischemic stroke symptom onset within the previous $22 \mathrm{~h}$, and had a NIHSS score of $>2$. Following enrolment of 250 patients with acute ischemic stroke, and after their initial CT scans, patients were randomized to either 48 -h placebo infusion (n $=123$ ) or 48 -h tirofiban infusion $(n=127)$. For the safety profile according to the bleeding rates, overall, hemorrhage was seen in $27.1 \%$ for placebo and $30.2 \%$ for tirofiban. This provided a nonsignificant relative risk of bleeding associated with tirofiban of 1.113. Similarly, the subgroup analysis of hemorrhage types for the placebo and tirofiban groups did not reach significance. The early (Day 2-4) monitoring of NIHSS scores saw no significant differences between the medians obtained for placebo and tirofiban treatment (4.0 vs. 4.0), and the decreases in these median NIHSS scores during this early, perfusion, period were the same in each arm (2.0 decrease). Similarly, the mean Barthel index (BI) scores five months from both treatments showed no significant differences (placebo, 77 vs. tirofiban, 81). However, for mortality after five to six months, there was a significant benefit for the tirofiban group over placebo, with a relative mortality risk of 0.271 .

\section{Summary of efficacy and safety studies of tirofiban in acute ischemic stroke}

A summary of studies using tirofiban in AIS is presented in Table 2. Tirofiban appears to improve outcomes in acute stroke, without causing any increase in bleeding complications. Further trial of tirofiban (SETIS: Study of efficacy of tirofiban in acute ischemic stroke) is ongoing.

\section{Differences between abciximab and tirofiban}

There are important differences in the mechanism of action and pharmacology of these agents (abciximab and tirofiban) that theoretically may pertain to therapeutic effect in AIS. Tirofiban is highly selective for inhibiting ligand binding onto activated GPIIb/IIIa receptors. In contrast, abciximab is not specific for GPIIb/IIIa and shares binding affinity for the vascular integrin $\alpha_{v} \beta_{3}$ and the leukocyte integrin $\alpha_{M} \beta_{2}$.

Abciximab exerts high binding affinity for GPIIb/IIIa. A bolus dose of $0.25 \mathrm{mg} / \mathrm{Kg}$ results in approximately $80 \%$ blockade of receptors and $>80 \%$ blockade of
ADP-induced platelet aggregation. It dissociates slowly from the receptors with an "off-rate" of 10-30 min. In contrast, tirofiban has a lower binding affinity for the receptor and dissociates more rapidly from it. Hence, it depends on higher plasma levels to sustain a target receptor blockade level above $80 \%$.

Lastly, abciximab is eliminated via antibody degradation of senescent platelets, whereas renal clearance is thought to be the main route of elimination for tirofiban.

\section{Conclusions}

Abciximab, though found to be safe and effective in AIS in early case series and Phase 1 and 2 trials, has not been shown to improve outcome in patients with AIS in a recent Phase 3 trial. Moreover, the rate of symptomatic ICH is also significantly higher with abciximab therapy. Various studies show that the cardiac doses of abciximab are probably too high in stroke patients. Therefore, this drug should not be used in patients with AIS till further trials are conducted whether with smaller dosage or in different window periods. However, tirofiban appears to be safe and effective in AIS, based on smaller case series and a few randomized trials. Further trials are, however, needed to establish its safety and efficacy in AIS. At present, the most common usage of GP IIb/ IIIa antagonists in stroke are as adjunctive agents to thrombolysis by intravenous and intra-arterial routes.

\section{References}

1. Anand K, Chowdhury D, Singh KB, Pandav CS, Kapoor SK. Estimation of mortality and morbidity due to strokes in India. Neuroepidemiology $2001 ; 20: 208-11$

2. Durai Pandian J, Padma V, Vijaya P, Sylaja PN, Murthy JM. Stroke and thrombolysis in developing countries. Int J Stroke 2007;2:17-26.

3. Yamanouchi H, Shimada H, Kuramoto K. Subtypes and proportions of cerebrovascular disease in an autopsy series in a Japanese geriatric hospital. Klin Wochenschr 1990;68:1173-7.

4. Schellinger PD, Fiebach JB, Mohr A, Ringleb PA, Jansen O, Hacke W. Thrombolytic therapy for ischemic stroke: A review, Part I--Intravenous thrombolysis. Crit Care Med 2001;29:1812-8.

5. Suwanwela NC, Phanthumchinda K, Likitjaroen Y. Thrombolytic therapy in acute ischemic stroke in Asia: The first prospective evaluation. Clin Neurol Neurosurg 2006;108:549-52.

6. Nandigam K, Narayan SK, Elangovan S, Dutta TK, Sethuraman KR, Das AK. Feasibility of acute thrombolytic therapy for stroke. Neurol India 2003;51:470-3.

7. Neki NS. Platelet glycoprotein $\mathrm{Ilb} / \mathrm{III}$ a receptor inhibitors-role in coronary artery disease. J Indian Acad Community Med 2004;5:259-65.

8. Brener SJ, Barr LA, Burchenal JE, Katz S, George BS, Jones AA, 
et al. Randomized, placebo-controlled trial of platelet glycoprotein IIb/ IIIa blockade with primary angioplasty for acute myocardial infarction. Circulation 1998;98:734-41.

9. The PURSUIT Trial Investigators. Inhibition of platelet glycoprotein $\mathrm{IIb} / \mathrm{III}$ a with eptifibatide in patients with acute coronary syndromes. N Engl J Med 1998; 339:436-43.

10. The Abciximab in Ischemic Stroke Investigators. Abciximab in acute ischemic stroke: A randomized, double-blind, placebo-controlled, doseescalation study. Stroke 2000;31:601-9.

11. Mitsias PD, Lu M, Silver B, Morris D, Ewing JR, Daley S, et al. MRIguided, open trial of abciximab for ischemic stroke within a 3- to 24-hour window. Neurology 2005;65:612-5.

12. Mandava P, Anderson JA, Kent TA. MRI-guided, open trial of abciximab for ischemic stroke within a 3- to 24-hour window. Neurology 2006;66:1132.

13. Morris DC, Silver B, Mitsias P, Lewandowski C, Patel S, Daley S, et al. Treatment of acute stroke with recombinant tissue plasminogen activator and abciximab. Acad Emerg Med 2003;10:1396-9.

14. Eckert B, Koch C, Thomalla G, Kucinski T, Grzyska U, Roether J, et al. Aggressive therapy with intravenous abciximab and intra-arterial rtPA and additional PTA/stenting improves clinical outcome in acute vertebrobasilar occlusion: Combined local fibrinolysis and intravenous abciximab in acute vertebrobasilar stroke treatment (FAST): Results of a multicenter study. Stroke 2005;36:1160-5.

15. Heo JH, Lee KY, Kim SH, Kim DI. Immediate reocclusion following a successful thrombolysis in acute stroke: A pilot study. Neurology 2003;60:1684-7.

16. Velat GJ, Burry MV, Eskioglu E, Dettorre RR, Firment CS, Mericle RA. The use of abciximab in the treatment of acute cerebral thromboembolic events during neuroendovascular procedures. Surg Neurol 2006;65:352-8, discussion 358-9.

17. Wholey MH, Wholey MH, Eles G, Toursakissian B, Bailey S, Jarmolowski C, et al. Evaluation of glycoprotein IIb/IIIa inhibitors in carotid angioplasty and stenting. J Endovasc Ther 2003;10:33-41.

18. Abciximab Emergent Stroke Treatment Trial (AbESTT) Investigators. Emergency administration of abciximab for treatment of patients with acute ischemic stroke: results of a randomized phase 2 trial. Stroke 2005;36:880-90

19. Adams HP Jr, Effron MB, Torner J, Frayne J, Teal P, Leclerc J, et al. Emergency administration of abciximab for treatment of patients with acute ischemic stroke: Results of an international phase III trial: Abciximab in Emergency Treatment of Stroke Trial (AbESTT-II). Stroke 2008;39:87-99.

20. Junghans U, Seitz RJ, Aulich A, Freund HJ, Siebler M. Bleeding risk of tirofiban: A nonpeptide GPIIb/IIIa platelet receptor antagonist in progressive stroke: An open pilot study. Cerebrovasc Dis 2001;12:308-12

21. Straub S, Junghans U, Jovanovic V, Wittsack HJ, Seitz RJ, Siebler M. Systemic thrombolysis with recombinant tissue plasminogen activator and tirofiban in acute middle cerebral artery occlusion. Stroke 2004;35:705-9.

22. Seitz RJ, Hamzavi M, Junghans U, Ringleb PA, Schranz C, Siebler M. Thrombolysis with recombinant tissue plasminogen activator and tirofiban in stroke: Preliminary observations. Stroke 2003;34:1932-5.

23. Mangiafico S, Cellerini M, Nencini P, Gensini G, Inzitari D. Intravenous glycoprotein $\mathrm{IIb} / \mathrm{III}$ inhibitor (tirofiban) followed by intra-arterial urokinase and mechanical thrombolysis in stroke. AJNR Am J Neuroradiol 2005;26:2595-601.

24. Liebeskind DS, Pollard JR, Schwartz ED, Cucchiara BL, McGarvey ML, Hurst RW. Vertebrobasilar thrombolysis with intravenous tirofiban: Case report. J Thromb Thrombolysis 2002;13:81-4.

25. Junghans U, Seitz RJ, Wittsack HJ, Aulich A, Siebler M. Treatment of acute basilar artery thrombosis with a combination of systemic alteplase and tirofiban, a nonpeptide platelet glycoprotein IIb/IIIa inhibitor: Report of four cases. Radiology 2001;221:795-801.

26. Junghans U, Seitz RJ, Ritzl A, Wittsack HJ, Fink GR, Freund HJ, et al. Ischemic brain tissue salvaged from infarction by the GP IIb/IIIa platelet antagonist tirofiban. Neurology 2002;58:474-6.

27. Seitz RJ, Meisel S, Moll M, Wittsack HJ, Junghans U, Siebler M. The effect of combined thrombolysis with rtPA and tirofiban on ischemic brain lesions. Neurology 2004;62:2110-2.

28. Junghans U, Siebler M. Cerebral microembolism is blocked by tirofiban: A selective nonpeptide platelet glycoprotein $\mathrm{Ilb} / \mathrm{III}$ receptor antagonist. Circulation 2003;107:2717-21.

29. Available from: http://www.docguide.com/news/content.nsf/news/85257 1020057CCF685257178005861A6. [last accessed on 2008 Jun 7]

Accepted on 18-09-2008

Source of Support: Nil, Conflict of Interest: None declared. 